\title{
Rhinology: Simulation Training (Part 1)
}

\section{Chrysostomos Tornari $^{1} \cdot$ Miroslav Tedla $^{2} \cdot$ Pavol Surda $^{1}$}

Published online: 24 January 2020

(C) The Author(s) 2020

\begin{abstract}
Purpose of Review Recently, there has been an expansion of novel technologies in simulation training. Different models target different aspects of training. The aim of this review was to examine existing evidence about training simulators in rhinology, their incorporation into real training programmes and translation of these skills into the operating room. The first part focuses on the virtual and augmented reality simulators. The second part describes the role of physical (i.e. non-computer-based) models of endoscopic sinus surgery.

Recent Findings Virtual reality simulators are still evolving and facing challenges due to their inherent cost and lack of realism in terms of the type of haptic feedback they provide. On the other hand, augmented reality seems to be a promising platform with a growing number of applications in preoperative planning, intraoperative navigation and education. Limitations in validity, registration error and level of evidence prevent the adoption of augmented reality on a wider scale or in clinical practice.

Summary Simulation training is a maturing field that shows reasonable evidence for a number of models. The incorporation of these models into real training programmes requires further evaluation to ensure that training opportunities are being maximized.
\end{abstract}

Keywords Virtual simulator $\cdot$ Simulation $\cdot$ Augmented reality $\cdot$ Rhinology $\cdot$ Training model $\cdot$ Sinus surgery

\section{Introduction}

Ear, nose and throat (ENT) training varies greatly both at the resident, fellow and post-certification level [1, 2]. However, it is challenging to critically evaluate and compare training programmes across nations as relevant studies rely entirely on trainee self-reports, without any objective comparators between groups. Furthermore, there is no evidence that directly compares the theoretical or practical attainment of trainees between nations.

This article is part of the Topical Collection on Simulation Training in Otolaryngology

Pavol Surda

pavol.surda@gmail.com

Chrysostomos Tornari

t.tornari@gmail.com

Miroslav Tedla

miro.tedla@gmail.com

1 Department of Otorhinolaryngology, Guy's and St Thomas' University Hospital, Great Maze Pond, London SE19RT, UK

2 Department of Otolaryngology, Head and Neck Surgery, Comenius University, University Hospital, Bratislava, Slovakia
An understanding of global training variation is important to ensure that practice is up-to-date as otolaryngology has changed greatly over the years. Since Hopkins' patent on his first endoscope in the 1960s, surgery of the nose, sinuses and skull base has rapidly evolved [3]. The educational enterprise that supports trainee growth and development has, therefore, changed to accommodate such changes in clinical practice $[4,5]$. However, there is still incomplete regulation and standardization of training - particularly notable at the fellowship level [6].

Furthermore, a number of training programmes have faced challenges to delivering adequate training in Otolaryngology [7•]. The European Working Time Directive has recently restricted surgical residents' working hours to an average of $48 \mathrm{~h}$ per week. The effect of these restrictions has been to decrease the operative exposure of UK ENT residents by up to 38\% [8]. Exposure to surgical sessions significantly vary even in developed countries. Residents in Germany reported difficulty in obtaining operative experience, which was felt to be allocated unfairly based on the approval of senior doctors. A 2015 survey-based study cites this reason for a disparity in trainees' reports of their surgical competence between Germany and France $[1,2,7 \cdot]$. Historically, surgical training has been "on the job", with surgeons and surgical trainees learning on live patients in the operating theatre and, when possible, through anatomic laboratory dissection. Recently, questions have been 
raised about the ethical foundation of exclusive reliance on intraoperative training [9]. In areas outside of medicine such as aviation, simulation has been successfully implemented. Repetitive practice of a well-defined task and feedback allow for an accelerated and ultimately safer learning curve [10]. In order to confront these challenges to cross-specialty surgical training, simulation training has gained increasing popularity both in terms of improving technical and non-technical skills [11].

The aim of this review was to examine existing evidence about training simulators in rhinology, their incorporation into real training programmes and the translation of these skills into operating room. The first part focuses on virtual and augmented reality simulators. The second part describes the role of physical (i.e. non-computer-based) models of endoscopic sinus surgery including animal models $[12,13]$.

\section{Definition and Requirements of Rhinological Training Models}

Successful performance in the operative environment requires surgeons to correctly execute a variety of technical and nontechnical skills in parallel. These skills can be simulated either in isolation or concurrently and, in order to adapt to the level of behaviour being modelled in a particular simulation, an understanding of the level of behaviour being modelled is helpful. One model that has been previously utilized to analyse simulation models involves the breaking down of models into three domains: skill-based, rule-based and knowledge-based behaviours [14]. Furthermore, surgeons will proceed through stages in their learning that will likely take them through a cognitive stage where they learn to understand a task through an integrative stage where deliberate practice and feedback take place. The final stage is that of automation whereby little cognitive input is required and performance is refined [10].

The ideal endoscopic sinus surgery (ESS) training model would encompass these relevant behaviours and stages whilst being realistic, interactive and low-cost with high repeatability and feedback. Virtual reality (VR) models struggle to attain some of these goals due to their inherent cost and lack of realism in terms of the type of haptic feedback they provide. Therefore, alternative models are attractive ways to fill these gaps in simulation training whilst reducing costs [15].

Simulators can be assessed and compared by using standard measures of validity which can encompass various combinations of the three behaviours described above:

- Face validity: Experts subjectively decide whether a model tests what it is designed to measure

- Content validity: Experts subjectively decide whether the logical steps and skills used in the procedure are representative of the modelled task
- Construct validity: An objective test that is able to discriminate between novices and experts

- Concurrent validity: An objective test that compares the new paradigm with the gold standard

- Discriminate validity: A subset of construct validity that discriminates objectively between candidates with similar experience rather than comparing experts to novices

- Predictive validity: An objective test of whether performance on the task predicts performance in the operative environment [16]

An ideal model for a training or fellowship programme would score highly on all of the above measures whilst maintaining an attainable cost. This is a challenging goal that is worthy of pursuit given that simulation training has been shown to be a costeffective option in other domains [15]. The different models outlined below tend to target different aspects of training which are reflected in the types of validity that each model attempts to attain and the behaviours that each model addresses (Table 1).

\section{Virtual Reality Simulators}

Simulation and VR has become an essential part of training in medicine over the last 40 years [17, 18, 19••, 20]. ENT has been a very active field in which to implement these advancing technologies. In particular, tools for temporal bone surgery have been described in over 200 studies, as this anatomical location shows great complexity and variability $[18,19 \cdot \bullet, 21]$. VR training for functional endoscopic sinus surgery might be appropriate in rhinology [22].

Wiet et al. reported their collaboration in developing a VR system that provides interaction with volume data, by employing real-time volume rendering and haptic feedback [23]. The first endoscopic sinus surgery VR simulators studies, authors used a computer-generated 3D model of patients' anatomy from $\mathrm{CT}$ or MR scans [24, 25]. The interaction

Table 1 Validation studies of VR simulators

\begin{tabular}{lll}
\hline Virtual reality simulators & $\begin{array}{l}\text { Validation } \\
\text { studies }\end{array}$ & Notes \\
\hline $\begin{array}{ll}\text { ES3 Madigan endoscopic } \\
\text { sinus surgery simulator }\end{array}$ & $\begin{array}{l}\text { Construct [28] } \\
\text { Construct [27] } \\
\text { Face [24] }\end{array}$ & \\
& $\begin{array}{l}\text { Predictive [30] } \\
\text { Predictive [58] } \\
\text { Predictive [31] }\end{array}$ & $\begin{array}{r}\text { Model was unable } \\
\text { to demonstrate } \\
\text { construct validity }\end{array}$ \\
Fextroscope & & \\
Flinders sinus surgery simulator & Construct [59] & \\
Mc Gill simulator & Face [34] & \\
\hline
\end{tabular}


between the anatomical simulations and applied instruments was archived through electromagnetic tracking systems. However, tactile feedback could was not achieved and acoustic signals were used when critical structures were injured [25]. Rudman et al. used cryo-sections to reconstruct relevant anatomy for their model. In a head model, electromagnetic forces were used to give haptic feedback to the user, who was asked to navigate the endoscope through the nasal cavity, as well as to perform surgical procedures like ethmoidectomy [24]. Another application of VR in rhinologic training is the establishment of a web-based resource. This would especially help residents in countries where specialists are rare $[7 \cdot, 26]$.

\section{Madigan Endoscopic Sinus Surgery Simulator}

From all available simulators in the early 2000s, the Lockheed Martin endoscopic sinus surgery simulator (ES3) became the most studied. The ES3 runs on a Silicon Graphics workstation, a personal computer-based haptic controller and an electromechanical haptic interface, with a model of an endoscope, a handle for surgical tools and a head model. The system provides haptic feedback, reproducing resistance and vibration on the surgical instrument's handle. The ES3 can simulate bleeding, and image deterioration simulating a dirty lens. The simulator provides different instruments for each dissection step to reproduce a standard endoscopic sinus surgery procedure [27].

Arora et al. studied fundamental perceptual, visuospatial and psychomotor abilities in a group of students and otolaryngology residents ( $n=38)$ using ES3, a minimally invasive surgical trainer VR (MISTVR), a pictorial surface orientation (PicSOr) and 3 visuospatial tests (cube comparison, card rotation and map planning) to validate the reliability of simulators. The scores of ES3 correlated well with previously validated measures. Hence, the ES3 was shown as reliable tool in rhinology training [28]. To identify anatomical structures after training with either medium, Solyar et al. tested 8 subjects with the ES3 against 7 others learning from textbooks. The ES3 group achieved higher scores in less time [29]. Fried et al. then translated ES3 training to the operating theatre, comparing a group of simulator-trained residents to residents who only had access to "conventional" learning material, where the latter was not specified. The first live surgery was recorded and evaluated by blinded expert surgeons. The results showed better outcomes for the ES3 group as regards time to completion of task (minutes), case difficulty, tool manipulation, tissue respect, task completion rate, surgical confidence (10-point scale) and number of errors. Errors were defined as dirty scope, wandering scope, failed attempt in orientation, lack of perspective in instrument view, collision, improper injection (of local anaesthesia), mucosal injury and bloody field $[7 \cdot, 30]$.

\section{Dextroscope}

The Dextroscope was developed in Singapore in 2003 and it is a commercial FDA approved simulator developed by volume interactions. It facilitates reconstruction of images from a patient's computed tomographic scan. The workstation features stereoscopic glasses, a stylus and a control handle (a joystick). The Dextroscope does not use a model head. The joystick operates the endoscope and the stylus operates the microdebrider or drill. The 3D graphics reflect anatomical shapes; however, force feedback is lacking, as are physiological data such as injection blanching or bleeding. The model is rather stiff, preventing gentle displacement of certain structures. The Dextroscope simulator did not improve operating room performance and was poorly rated by the 3 participating surgeons in the study by Caversaccio et al. [31].

\section{Flinders Sinus Surgery Simulator}

Flinders sinus surgery simulator (FSSS) is a promising prototype that was developed at Flinders University. It is a highresolution VR haptic simulator that utilises phantom haptic devices to mimic endoscopic sinus surgery [32]. FSSS has been validated for teaching sinus anatomy and nasendoscopy to medical students, interns and residents. However, FSSS requires further development before it can be regarded as a valid tool for more advanced surgical training [33]. Moreover, it is not currently available for purchase and is not being used as part of a training programme.

\section{McGill Simulator for Endoscopic Sinus Surgery}

In 2014, the most recent VR simulator for FESS, the McGill simulator, was introduced. Additional tools applied include sinus washing and the simulated use of microdebriders. Moreover, the system can calculate the amount of tissues/ structures removed by the microdebrider [34]. Despite promising results of previous studies for applicability and validity, Dharmawadana et al. validated four different simulators for four different groups from students to registrars. Conclusion was that VR simulators are helpful for the initial steps of surgical training, but would not be ready for more advanced skills as required by registrars $[7 \cdot, 33]$.

\section{Augmented Reality}

There is often some confusion in understanding the difference between augmented reality (AR), VR and their different uses. AR uses technology to superimpose information (such as images and sounds) on the world we see-it adds to normal reality. VR creates a computer-generated environment for the user to interact with and be fully immersed in - it replaces 
normal reality. However, the newest AR software uses the features of both technologies to provide a better understanding of sinus anatomy which is probably the most important prerequisite for endoscopic sinus surgery.

A fundamental benefit of AR technology is the ability for surgeons to review preoperative imaging, "map out" a surgical approach and view this information during an operation. From an educational perspective, AR can benefit surgical trainees through platforms in anatomy education, simulations and intraoperative guidance [35•].

\section{Preoperative Planning and Education}

The most basic example of preoperative AR is the fusion of MRI scans and pictures of the patient's sagittal photograph using the Android/iPhone overlay application. This technique was used to depict the lesion's surface projection onto the skin of the head [36].

Advanced AR planning software allows the transformation of the sinus anatomy into 3-D models based on reconstruction from slices of a CT scan which is then combined with the second annotated scan highlighting the area of interest (tumour, frontal sinus outflow, vascular structure). Precise alignment of virtual datasets is critical. In the case of removing a tumour, for example, the surgeon would be able to not only visualize it but also move around it to better-understand relationships to local anatomical structures [37]. The experience can be maximized with 3-D glasses which enhance the perception of depth or the construct can be 3D-printed into a real model. A literature review did not identify applications of AR in head and neck anatomy education; however, previous studies suggested that $3 \mathrm{D}$ learning may enhance spatial awareness and improve learning contextualization [38]. This was supported by a large-scale study by Kugelmann et al. of 880 first-year medical students showing the impact of incorporating AR into a traditional anatomy course. The results showed increased motivation and engagement with enhanced student understanding of anatomy [39].

\section{Intraoperative Guidance}

Intraoperative navigation systems in endoscopic sinus surgery have emerged as a critical tool in the last decades [35•]. In some ways, surgical navigation systems are similar to the GPS (global positioning system) used by car drivers: both in providing step-by-step directions and showing users their precise location. However, a rhinologist in the operating room faces a challenge to transform the three-dimensional surgical field (3D) to two-dimensional (2D) sections on the navigation screen. The surgeon is, therefore, confronted with the mental task of integrating these two image data sets. AR technology might be a way to overcome this problem. The virtual data for intraoperative navigation can be simply informative (such as textual or numerical values relevant to what is under observation) or consisting of three-dimensional virtual objects inserted within the real environment in spatially defined positions.

There are several systems offering this unique feature but Scopis Hybrid Navigation (Scopis, GmbH, Berlin, Germany) has been pushing the boundaries of AR in endoscopic sinus surgery (ESS). The current software offers a novel preoperative planning phase, known as Building Blocks for frontal recess anatomy (as proposed by Wormald) [40]. Furthermore, this navigation system incorporates technology for the calibration of standard endoscopic images with CT scan-derived models, a variation of an approach originally proposed as imageenhanced endoscopy. Intraoperatively, the AR views provided useful information before starting the dissection, as the AR permitted the surgeon to "see" the relevant structures without formally removing the uncinated process or any other tissue (Fig. 1). This may have important implications for balloon catheter dilatation of sinus ostia. IGS with AR may also function as a "target avoidance" mechanism. AR may mark structures so that their location is clear, before they are exposed during surgery. Figure 2 shows this concept of 'anti-targeting' by illustrating the presence of the optic nerve without direct exposure of the optic nerve. The internal carotid artery could be highlighted in a similar fashion. Currently, Scopis Hybrid Navigation displays all images in 2D representations, not a holographic 3D image [41, 42].

$\mathrm{AR}$ in sinus surgery is still a novel navigational system; therefore, there are only few studies documenting its efficacy in this context [37, 41, 42]. Due to close proximity to dangerous structures, ESS in early years of training can be associated with increased mental demand, effort and frustration. AR seems to reduce the task workload for trainees performing ESS and may be a valuable intraoperative teaching aid [43]. In skull base surgery, AR overlays of both endoscope trajectory and neurovascular anatomy were highly valuable in reaching the sellar floor safely in revision procedures, with no additional operative time or hardware setup required [44, 45]. One of the limitations may be a single head-up display which can distract the user and cause blindness. This can be corrected by a sub-monitor [46॰].

Another type of AR is the Google Glass (GG) which offers a quite different experience. GG is essentially a smartphone in the form of a pair of conventional spectacles with built-in small screen which allows hands-free access to electronic information through voice command [47, 48]. Its connectivity via WiFi makes GG potentially useful for the needs of telemedicine [49]. The main advantages intraoperatively are facilitating access to electronic medical literature including instructional videos or patient records for a quick reference, connection to the operating theatre's information system to monitor a patient's vital signs and speech-to-text dictation such as major intraoperative findings. Moreover, GG can be used as a tool for telemedicine where the members of the surgical team or other specialties could communicate, hence GG may facilitate intraoperative decision making [50]. 


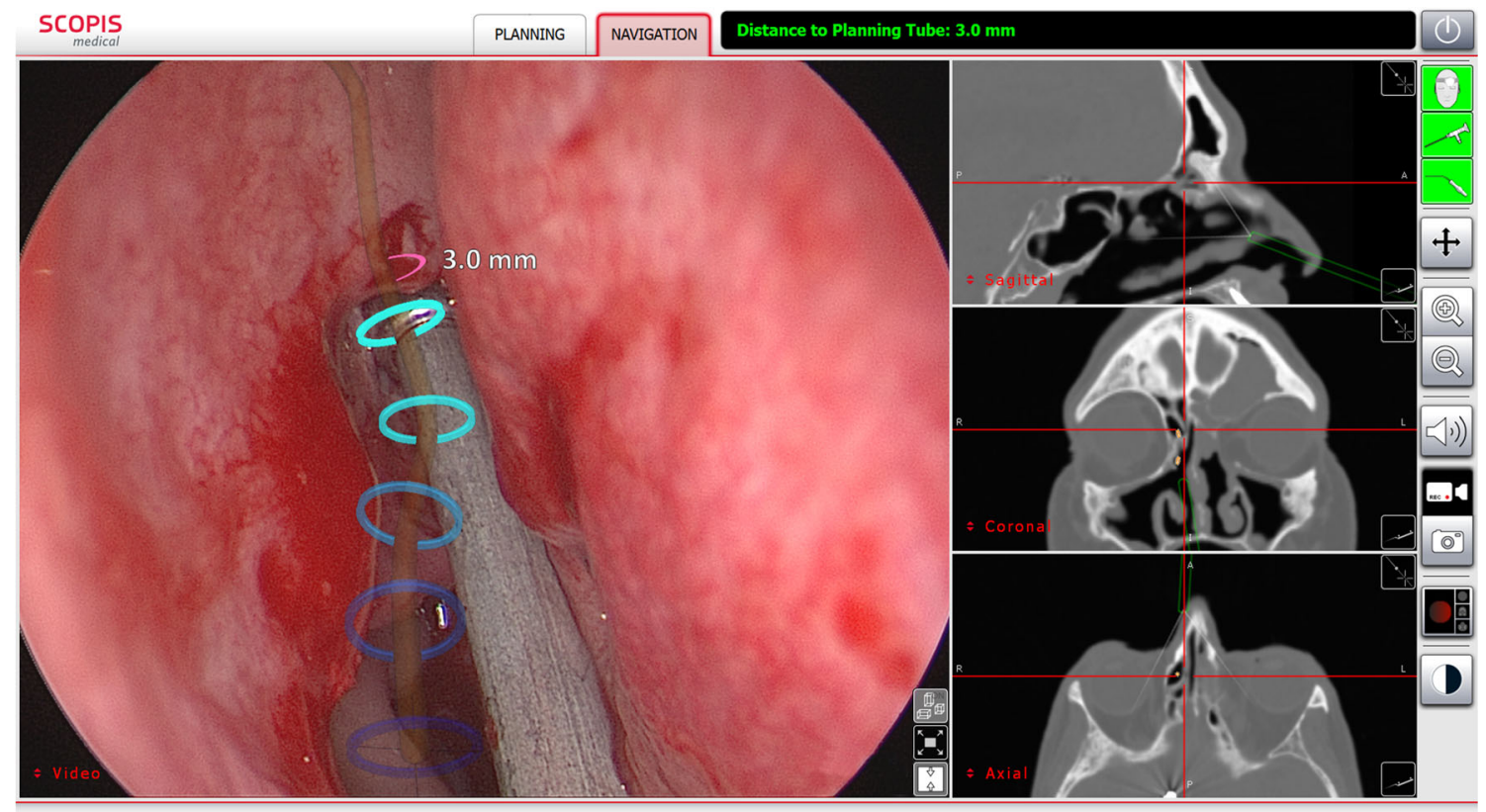

Fig. 1 Intraoperatively, the AR views provided useful information before starting the dissection, as the AR permitted the surgeon to "see" the relevant structures without formally removing the uncinated process or any other tissue. (With permission from Stryker Instruments, Portage, MI)

Although GG represents a novel breakthrough technology in the field of surgery, several limitations remain. This includes a short battery life and poor image quality (screen resolution is $640 \times 360$ pixels) [51-53]. In telemedicine, the use of GG was limited by network delay and also line of sight where the operating surgeon had to tilt the head unnaturally to keep the image on the display so the surgeon B could see the surgical field [50].

\section{Conclusion}

Piromchai et al. showed in their meta-analysis that the VR simulators (temporal bone, sinonasal) could be implemented as an adjunct in training programmes but cannot replace conventional methods. This is mainly because the actual surgical outcome following VR training has not been studied in any

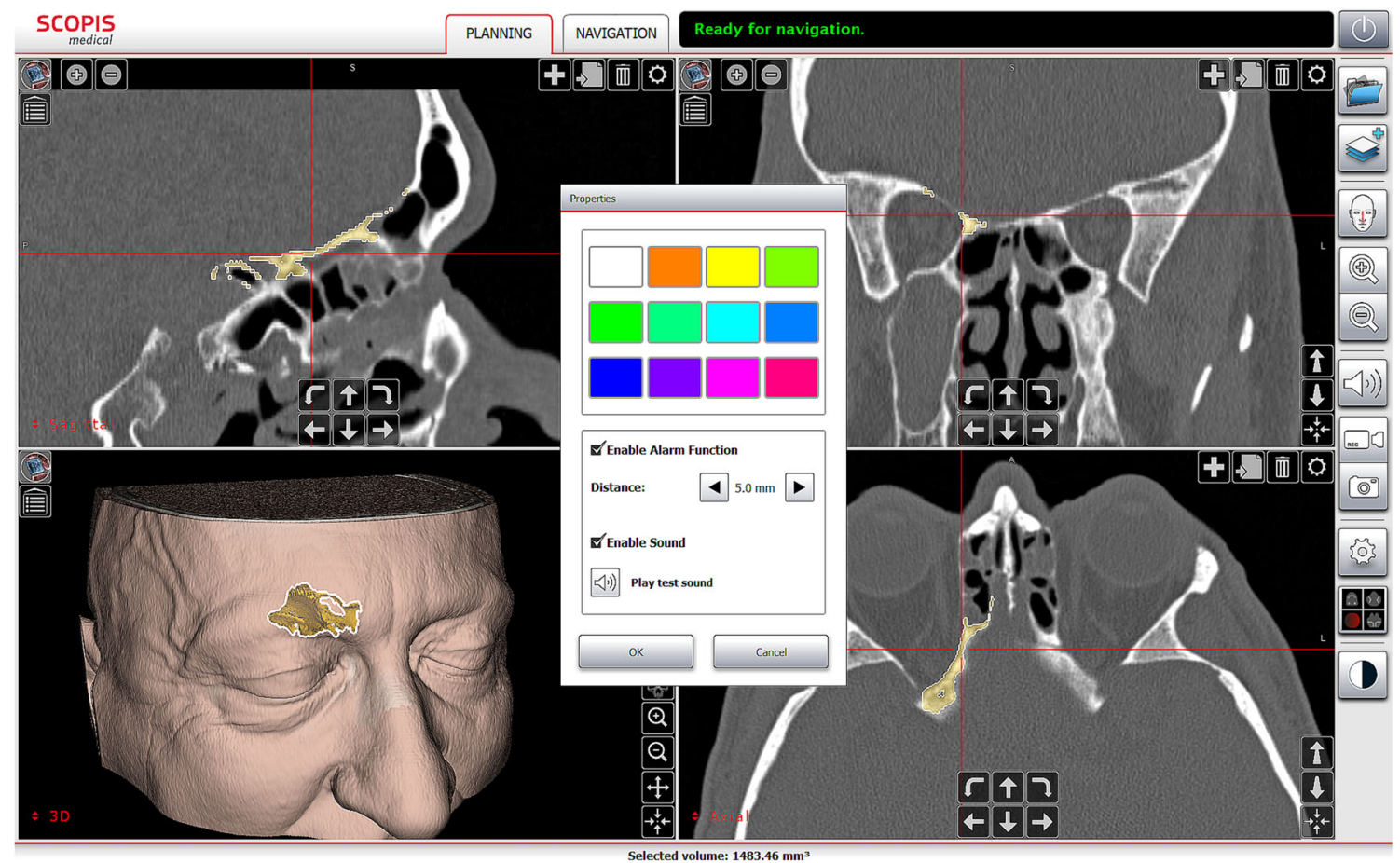

Fig. 2 Concept of 'anti-targeting' is shown by illustrating the presence of the optic nerve without direct exposure of the optic nerve. (With permission from Stryker Instruments, Portage, MI) 
great depth. This is the primary focus of future larger scale studies [19••]. A survey among participants of ESS courses showed that tasks related to spatial orientation are judged as the hardest, whereas manual tasks are considered less difficult. This suggests that simulators will not necessarily require haptic feedback to train the most important knowledge and skills needed for FESS [54]. The more affordable alternatives might be $3 \mathrm{D}$ printed anatomical models $[7 \cdot, 55-57]$.

AR seems to be a promising platform with growing number of applications in preoperative planning, intraoperative navigation and education. However, significant limitations remain, namely lack of robust validation and issues with registration error that prevent the widespread use of AR in clinical practice. Despite that, AR technology is still in its relative infancy, and these limitations will likely improve as research continues to develop.

Acknowledgements This article was made open access with the financial support of King's College London.

\section{Compliance with Ethical Standards}

Conflict of Interest The authors declare that they have no conflict of interest.

Human and Animal Rights and Informed Consent This article does not contain any studies with human or animal subjects performed by any of the authors.

Open Access This article is licensed under a Creative Commons Attribution 4.0 International License, which permits use, sharing, adaptation, distribution and reproduction in any medium or format, as long as you give appropriate credit to the original author(s) and the source, provide a link to the Creative Commons licence, and indicate if changes were made. The images or other third party material in this article are included in the article's Creative Commons licence, unless indicated otherwise in a credit line to the material. If material is not included in the article's Creative Commons licence and your intended use is not permitted by statutory regulation or exceeds the permitted use, you will need to obtain permission directly from the copyright holder. To view a copy of this licence, visit http://creativecommons.org/licenses/by/4.0/.

\section{References}

Papers of particular interest, published recently, have been highlighted as:

- Of importance

•- Of major importance

1. Oker N, Alotaibi NH, Reichelt AC, Herman P, Bernal-Sprekelsen M, Albers AE. European otorhinolaryngology training programs: results of a European survey about training satisfaction, work environment and conditions in six countries. Eur Arch Otorhinolaryngol. 2017;274(11):4017-29.

2. Oker N, Escabasse V, Al-Otaibi N, Coste A, Albers AE. Acquisition of diagnostic and surgical skills in otorhinolaryngology: a comparison of France and Germany. Eur Arch Otorhinolaryngol. 2015;272(11):3565-73.

3. Fokkens WJ. The endoscope: new opportunities requiring new skills. Rhinology. 2009;47(4):337-8.

4. Seys SF, Bousquet J, Bachert C, et al. mySinusitisCoach: patient empowerment in chronic rhinosinusitis using mobile technology. Rhinology. 2018;56(3):209-15.

5. Mace AD, Narula AA. Survey of current undergraduate otolaryngology training in the United Kingdom. J Laryngol Otol. 2004;118(3):217-20.

6. Ryan MW, Johnson F. Fellowship training in otolaryngology-head and neck surgery. Otolaryngol Clin N Am. 2007;40(6):1311-22 viii-ix.

7. Surda P, Barac A, Deghani P, et al. Training in ENT; a comprehensive review of existing evidence. Rhinology Online. 2018;1(1):7784. A comprehensive review of up-to-date training in rhinology focusing on surgical and non-surgical aspects.

8. Pothier DD, Toll EC, Grant DG, Giddings CEB. Trends in operative training opportunities for junior and senior trainees in otolaryngology. Clin Otolaryngol. 2009;34:6.

9. Sachdeva AK, Russell TR. Safe introduction of new procedures and emerging technologies in surgery: education, credentialing, and privileging. Surg Clin North Am. 2007;87(4):853-66 vi-vii.

10. Reznick RK, MacRae H. Teaching surgical skills-changes in the wind. N Engl J Med. 2006;355(25):2664-9.

11. Bamford R, Langdon L, Rodd CA, Eastaugh-Waring S, Coulston JE. Core trainee boot camp, a method for improving technical and non-technical skills of novice surgical trainees. A before and after study. Int J Surg. 2018;57:60-5.

12. Touska P, Awad Z, Tolley NS. Suitability of the ovine model for simulation training in rhinology. Laryngoscope. 2013;123(7): 1598-601.

13. Awad Z, Touska P, Arora A, Ziprin P, Darzi A, Tolley NS. Face and content validity of sheep heads in endoscopic rhinology training. Int Forum Allergy Rhinol. 2014;4(10):851-8.

14. Dankelman J. Surgical simulator design and development. World J Surg. 2008;32(2):149-55.

15. Badash I, Burtt K, Solorzano CA, Carey JN. Innovations in surgery simulation: a review of past, current and future techniques. Ann Transl Med. 2016;4(23):453.

16. Ooi EH, Witterick IJ. Rhinologic surgical training. Otolaryngol Clin N Am. 2010;43(3):673-89 xi.

17. Javia L, Deutsch ES. A systematic review of simulators in otolaryngology. Otolaryngol Head Neck Surg. 2012;147(6):999-1011.

18. Arora A, Lau LY, Awad Z, Darzi A, Singh A, Tolley N. Virtual reality simulation training in otolaryngology. Int J Surg. 2014;12(2):87-94.

19.• Piromchai P, Avery A, Laopaiboon M, Kennedy G, O'Leary S. Virtual reality training for improving the skills needed for performing surgery of the ear, nose or throat. Cochrane Database Syst Rev. 2015;(9):CD010198. https://doi.org/10.1002/14651858. CD010198.pub2. This showed that the VR simulators (temporal bone, sinonasal) could be implemented as an adjunct in training programs but cannot replace conventional methods. This is mainly because the actual surgical outcome following VR training has not been studied in any great depth. This is the primary focus of future larger scale studies.

20. Surda P, Tedla M, Baldwin D. Virtual reality as a training method in the area of FESS and Skull Base. Otorinolaryng. a Foniat. 2015;64(2):98-101

21. Lui JT, Hoy MY. Evaluating the effect of virtual reality temporal bone simulation on mastoidectomy performance: a meta-analysis. Otolaryngol Head Neck Surg. 2017;156(6):1018-24.

22. Baudoin T, Grgic MV, Zadravec D, Geber G, Tomljenovic D, Kalogjera L. Algorithm for navigated ESS. Rhinology. 2013;51(4):335-42. 
23. Wiet GJ, Yagel R, Stredney D, Schmalbrock P, Sessanna DJ, Kurzion Y, et al. A volumetric approach to virtual simulation of functional endoscopic sinus surgery. Stud Health Technol Inform. 1997;39:167-79.

24. Rudman DT, Stredney D, Sessanna D, Yagel R, Crawfis R, Heskamp D, et al. Functional endoscopic sinus surgery training simulator. Laryngoscope. 1998;108(11 Pt 1):1643-7.

25. Ecke U, Klimek L, Muller W, Ziegler R, Mann W. Virtual reality: preparation and execution of sinus surgery. Comput Aided Surg. 1998;3(1):45-50.

26. Navarro Newball AA, Hernandez CJ, Velez JA, et al. Virtual surgical telesimulations in otolaryngology. Stud Health Technol Inform. 2005; $111: 353-5$.

27. Fried MP, Uribe JI, Sadoughi B. The role of virtual reality in surgical training in otorhinolaryngology. Curr Opin Otolaryngol Head Neck Surg. 2007;15(3):163-9.

28. Arora H, Uribe J, Ralph W, Zeltsan M, Cuellar H, Gallagher A, et al. Assessment of construct validity of the endoscopic sinus surgery simulator. Archiv Otolaryngol Head Neck Surg. 2005;131(3): 217-21.

29. Solyar A, Cuellar H, Sadoughi B, Olson TR, Fried MP. Endoscopic sinus surgery simulator as a teaching tool for anatomy education. Am J Surg. 2008;196(1):120-4

30. Fried MP, Sadoughi B, Gibber MJ, et al. From virtual reality to the operating room: the endoscopic sinus surgery simulator experiment. Otolaryngol Head Neck Surg. 2010;142(2):202-7.

31. Caversaccio M, Eichenberger A, Hausler R. Virtual simulator as a training tool for endonasal surgery. Am J Rhinol. 2003;17(5):28390.

32. Ruthenbeck GS, Hobson J, Carney AS, Sloan S, Sacks R, Reynolds KJ. Toward photorealism in endoscopic sinus surgery simulation. Am J Rhinol Allergy. 2013;27(2):138-43.

33. Dharmawardana N, Ruthenbeck G, Woods C, Elmiyeh B, Diment $\mathrm{L}$, Ooi EH, et al. Validation of virtual-reality-based simulations for endoscopic sinus surgery. Clin Otolaryngol. 2015;40(6):569-79.

34. Varshney R, Frenkiel S, Nguyen LH, et al. Development of the McGill simulator for endoscopic sinus surgery: a new highfidelity virtual reality simulator for endoscopic sinus surgery. Am J Rhinol Allergy. 2014;28(4):330-4.

35. Wong K, Yee HM, Xavier BA, Grillone GA. Applications of augmented reality in otolaryngology: a systematic review. Otolaryngol Head Neck Surg. 2018;159(6):956-67. This study offers comprehensive review of current augmented reality systems including future prospects.

36. Hou Y, Ma L, Zhu R, Chen X, Zhang J. A Low-Cost iPhoneAssisted Augmented Reality Solution for the Localization of Intracranial Lesions. PLoS One. 2016;11(7):e0159185. https://doi. org/10.1371/journal.pone.0159185.

37. Agbetoba A, Luong A, Siow JK, Senior B, Callejas C, Szczygielski $\mathrm{K}$, et al. Educational utility of advanced three-dimensional virtual imaging in evaluating the anatomical configuration of the frontal recess. Int Forum Allergy Rhinol. 2017;7(2):143-8.

38. Dalgarno B, Lee MJW. What are the learning affordances of 3-D virtual environments? Br J Educ Technol. 2010;41(1):10-32.

39. Kugelmann D, Stratmann L, Nuhlen N, et al. An augmented reality magic mirror as additive teaching device for gross anatomy. Ann Anat. 2018;215:71-7.

40. Wormald P-J. Three-dimensional building block approach to understanding the anatomy of the frontal recess and frontal sinus. Oper Tech Otolaryngol Head Neck Surg. 2006;17(1):2-5.

41. Citardi MJ, Agbetoba A, Bigcas JL, Luong A. Augmented reality for endoscopic sinus surgery with surgical navigation: a cadaver study. Int Forum Allergy Rhinol. 2016;6(5):523-8.

42. Li L, Yang J, Chu Y, Wu W, Xue J, Liang P, et al. A novel augmented reality navigation system for endoscopic sinus and skull base surgery: a feasibility study. PLoS One. 2016;11(1):e0146996.
43. Dixon BJ, Chan H, Daly MJ, Vescan AD, Witterick IJ, Irish JC. The effect of augmented real-time image guidance on task workload during endoscopic sinus surgery. Int Forum Allergy Rhinol. 2012;2(5):405-10.

44. Yoshino M, Saito T, Kin T, Nakagawa D, Nakatomi H, Oyama H, et al. A microscopic optically tracking navigation system that uses high-resolution 3D computer graphics. Neurol Med Chir. 2015;55(8):674-9.

45. Kawamata T, Iseki H, Shibasaki T, Hori T. Endoscopic augmented reality navigation system for endonasal transsphenoidal surgery to treat pituitary tumors: technical note. Neurosurgery. 2002;50(6): 1393-7.

46. Dixon BJ, Daly MJ, Chan HH, Vescan A, Witterick IJ, Irish JC. Inattentional blindness increased with augmented reality surgical navigation. Am J Rhinol Allergy. 2014;28(5):433-7. Study shows that one of the limitations of AR may be a single head-up display which can distract the user and cause blindness. This can be corrected by a sub-monitor.

47. Glauser W. Doctors among early adopters of Google Glass. CMAJ. 2013;185(16): 1385 .

48. Aldaz G, Shluzas LA, Pickham D, Eris O, Sadler J, Joshi S, Leifer L. Hands-free image capture, data tagging and transfer using Google Glass: a pilot study for improved wound care management. PLoS One. 2015;10(4):e0121179. https://doi.org/10.1371/journal. pone.0121179.

49. Ye J, Zuo Y, Xie T, Wu M, Ni P, Kang Y, Yu X, Sun X, Huang Y, Lu $\mathrm{S}$. A telemedicine wound care model using $4 \mathrm{G}$ with smart phones or smart glasses: A pilot study. Medicine (Baltimore). 2016;95(31): e4198. https://doi.org/10.1097/MD.0000000000004198.

50. Chang JY, Tsui LY, Yeung KS, Yip SW, Leung GK. Surgical vision: Google Glass and surgery. Surg Innov. 2016;23(4):422-6.

51. Paro JA, Nazareli R, Gurjala A, Berger A, Lee GK. Video-based self-review: comparing Google Glass and GoPro technologies. Ann Plast Surg. 2015;74(Suppl 1):S71-4.

52. Rahimy E, Garg SJ. Google Glass for recording scleral buckling surgery. JAMA Ophthalmol. 2015;133(6):710-1.

53. Hashimoto DA, Phitayakorn R, Fernandez-del Castillo C, Meireles $\mathrm{O}$. A blinded assessment of video quality in wearable technology for telementoring in open surgery: the Google Glass experience. Surg Endosc. 2016;30(1):372-8.

54. Bakker NH, Fokkens WJ, Grimbergen CA. Investigation of training needs for functional endoscopic sinus surgery (FESS). Rhinology. 2005;43(2):104-8.

55. Briner HR, Simmen D, Jones N, Manestar D, Manestar M, Lang A, et al. Evaluation of an anatomic model of the paranasal sinuses for endonasal surgical training. Rhinology. 2007;45(1):20-3.

56. AlReefi MA, Nguyen LH, Mongeau LG, Haq BU, Boyanapalli S, Hafeez N, et al. Development and validation of a septoplasty training model using 3-dimensional printing technology. Int Forum Allergy Rhinol. 2017;7(4):399-404.

57. Chang DR, Lin RP, Bowe S, Bunegin L, Weitzel EK, McMains K, et al. Fabrication and validation of a low-cost, medium-fidelity silicone injection molded endoscopic sinus surgery simulation model. Laryngoscope. 2017;127(4):781-6.

58. Edmond CV Jr. Impact of the endoscopic sinus surgical simulator on operating room performance. Laryngoscope. 2002;112(7 Pt 1): $1148-58$.

59. Diment LE, Ruthenbeck GS, Dharmawardana N, Carney AS, Woods CM, Ooi EH, et al. Comparing surgical experience with performance on a sinus surgery simulator. ANZ J Surg. 2016;86(12):990-5.

Publisher's Note Springer Nature remains neutral with regard to jurisdictional claims in published maps and institutional affiliations. 